\title{
Industry Fire Safety System using Embedded Technology with Internet of Things
}

\author{
Ch. Srigiri, K. V. Lalitha, T V Prasad, S. Krishna Vamsi
}

\begin{abstract}
This paper keeps tabs to the security also security of the article of clothing plant disappointments and outrage on his/her staff need getting to be a most amazing issue currently a times. Those articles of clothing plant workers face a considerable measure about issues and broken crazy of chimney a standout amongst them beyond any doubt. Those depositors aren't demonstrating to whatever enthusiasm toward this segment and fact that this division may be getting toner. In this examine a chimney identification system may be propounded and conjointly gives data of the area influenced. Here we utilized ARM7 which are inserted with diverse sorts from the sensors. We give acceptable connect verification system to Abstain from cautioning. The system could right away send a SMS of the admin. Those admin will verify or deny the data. If those admin verify softening out about fire At that point system could immediately raise an alert and SMS will a chance to be sent of the close-by blaze unit.
\end{abstract}

Keywords: Fire safety, ARM7, ESP8266, sensors, authentication, GSM.

\section{INTRODUCTION}

Today's most recent advances need been being used for verification security. That home security includes a portion. Discriminating parameters like LPG gas spillage system,. Fire/smoke disturbing system, robbery \& intruders. Checking device. A significant number complex publicizing systems. That would notwithstanding accessible for this end goal. Most recent. Controllers, sensors, feature cameras and boisterous buzzers. Need aid used to deliver these issues recently? Far reaching and more lapse spare frameworks would available,. Which need aid both exact and more cosset compelling. We need utilized ARM-7 Microcontroller. Which may be the mossy cup oak propelled processor from claiming today's. Innovation. In this task an endeavor may be made for those. "Design $\&$ advancement from claiming a ARM-7 based installed. System to home security. The produced framework employments. A Philips LPC -2148 streak programmable 16/32-bit. ARM-7 built microcontroller for the precision control. About different sensors. This will be automatic, compact, and reliable. Also low cosset system. That plan utilized within this one task. Could make executed will have home security which

Revised Manuscript Received on September 22, 2019.

Ch.Srigiri, Department of ECE, Godavari Institute of Engineering \& Technology, Rajahmundry, A.P, India. srigiri0029@gmail.com

K.V.Lalitha, Department of ECE, Godavari Institute of Engineering \& Technology, Rajahmundry, A.P, India.

T V Prasad, Department of CSE , Godavari Institute of Engineering \& Technology, Rajahmundry, A.P, India.

S.Krishna Vamsi, Department of ECE, Godavari Institute of Engineering \& Technology, Rajahmundry, A.P, India. includes. LPG gas spillage alarming, fire/smoke disturbing and. Intruders disturbing framework.

An embedded system is a computer device which is the merger of software code and hardware devices to accomplish a specific function. The major devices used in this embedded devices are microprocessors and microcontrollers. It consists of specially made hardware devices built round a central processing unit (IOT). The software code is dumped into the microchip with the hardware devices.

Microprocessors are generally referred to as a general purpose inputs and give the output. When it comes to microcontroller, it accepts the information as inputs and additionally manipulates, interfaces the information and can be controlled and offers result finally. An embedded system can be a merger of hardware devices and code, and may be further mechanical or completely different modules which square measure designed to execute a particular perform. For example the appliances employed in the kitchen room are everything has one, and tens of voluminous the square measure used each day, however only a few devices processor and computer code square measure involved at intervals the preparation of their lunch.

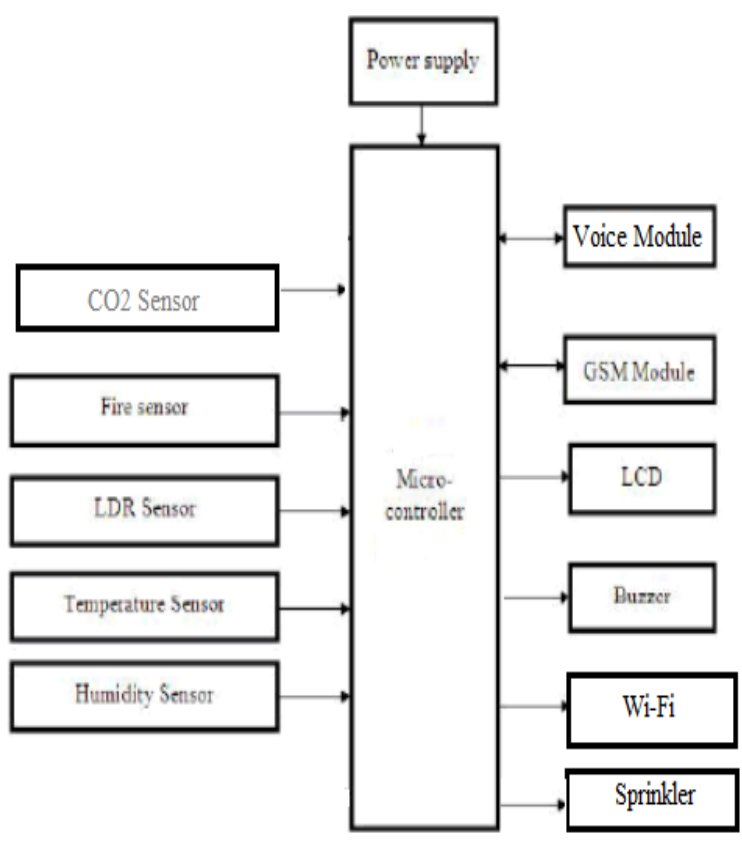

Figure.1.1 Block Diagram

Published By:

Blue Eyes Intelligence Engineering 


\section{Industry Fire Safety System using Embedded Technology with Internet of Things}

\section{PROPOSED SYSTEM}

This framework will be skilled should Figure chimney and we moreover Gave false chimney suspecting framework will keep away from whatever cautioning. Here we utilization ARM7 will control. Numerous sensors similar to fire, temperature, what's more co sensor would utilized which are associated with ARM7. At whatever point chimney may be distinguished the framework will immediately communicate something specific of the admin. Assuming that those admin verify breaking crazy from claiming shoot that point framework could immediately raise an alert and an SMS will a chance to be sent of the close-by blaze unit. The sensor majority of the data will a chance to be updated in the web page.

\section{METHODOLOGY}

\subsection{Fire Sensors}

This sensor is utilized for sensing Furthermore securing against hearth and may be a straightforward and conservative gadget. It employments ir sensor also a comparator with feeling arouse on 1-2 meters of extending contingent upon shoot thickness. It comprises from claiming 3 pins ground, vcc, also out. It comprises of headed which will be utilized as fire pointer. To changing go alignment preset may be utilized.

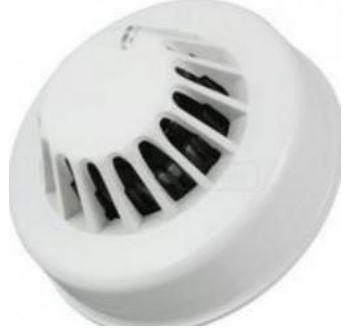

Fig.2. Fire Sensor

\subsection{Temperature Sensor (Lm35)}

The temperature sensor will be the associate IC sensor, which is utilized the temperature through a connected yield voltage is linearly equivalent to the Celsius temperature. It will be a plus over temperature sensor. It provides the temperature in degree centigrade $\left({ }^{\circ} \mathrm{C}\right)$. There will be no necessity of transformation from Kelvin scale to Celsius.

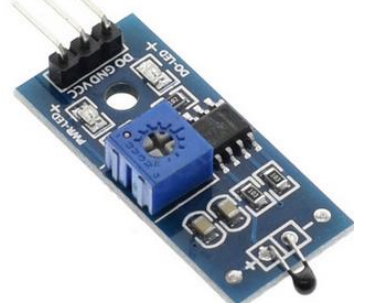

Figure.2.1. Temperature Sensor

\subsection{Co Sensor}

This sensor is utilized for sensing Furthermore securing against hearth and may be a straightforward and conservative gadget. It employments ir sensor and also comparator with feeling arouse on 1-2 meters of extending contingent upon shoot thickness. It comprises from claiming 3 pins ground, vcc, also out. It comprises of headed which will be utilized as fire pointer. To changing go alignment preset may be utilized.

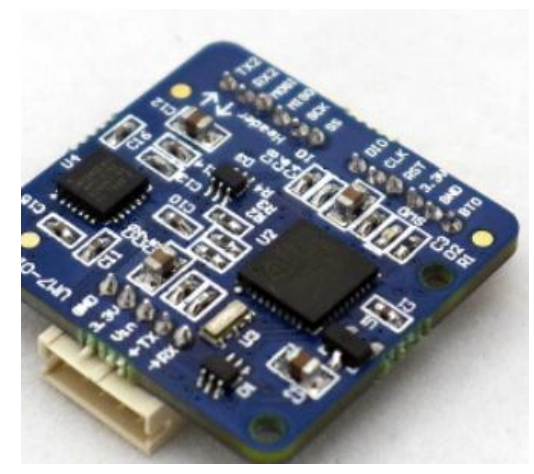

Figure .3: CO Sensor

\subsection{Wi-fi Module [Esp8266]}

Uses radio waves which provide connection to networks is connected using an adapter which would create a hotspot and allows the internet services. We use ESP8266 module. It is a microchip with low cost and follows TCP/IP stack. The ESP represents express if systems. It is a 32 bit microcontroller. The memory of ESP8266 is $32 \mathrm{~KB}$ instruction, $80 \mathrm{~KB}$ user data. It has a 1 MIB of built in flash.

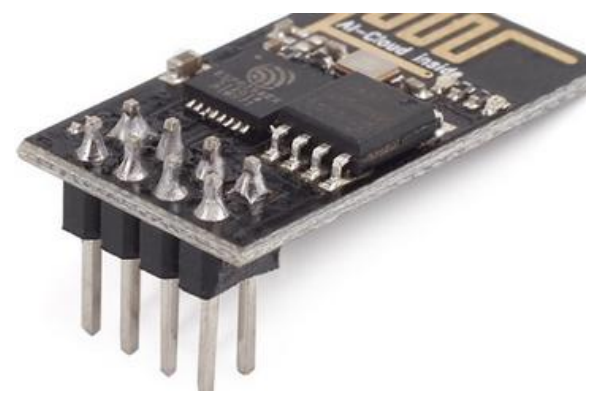

Figure.3.1: WI-FI Module

\subsection{Voice Module}

In voice module, the switching will be done among the traditional broadcasting and voice alert broadcasting. This module is used to check the output circuits, control status indicators, and power. Whereas the auto feedback is fixed then the voice module will transfer the feedback signal automatically to the panel while it changes to fireplace alarm broadcasting. These voice modules are utilized within the fire alarm systems to give manual voice messages and pre-recorded messages. These modules are the unit systems, which provide a personal response with the energy to conduct the systematic emigration and appreciate the humans who exist in that location.

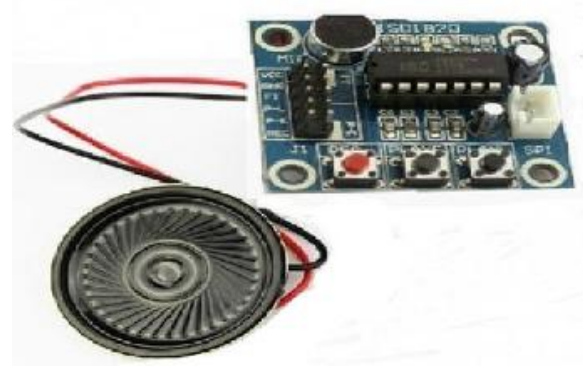

Figure 3.2: Voice Module 


\subsection{FLOW CHART}

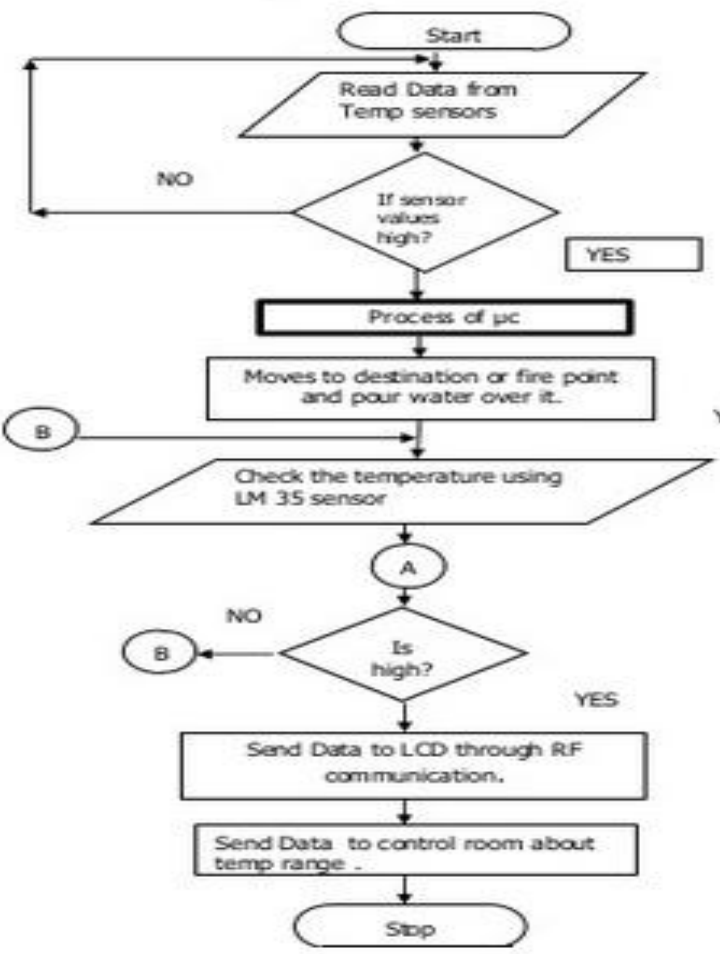

Figure.3.3: Flowchart

\section{SOFTWARE IMPLEMENTATION}

The system software is written by by using $\mathrm{C}$ and embedded $C$ in micro vision Keil-4 software. Then the hex is downloaded in the ARM core by using Flash magic software. The system software does not uses any generalized operating system program, as the developed system is a dedicated embedded system.

The systems application is developed by using Keil micro vision software with embedded $\mathrm{C}$ programming. Then the hex file is downloaded in the ARM device by using Flash magic tool, This syetm software does not support any generalized OS program, as the developed systems is a specific embedded systems

\section{RESULT}

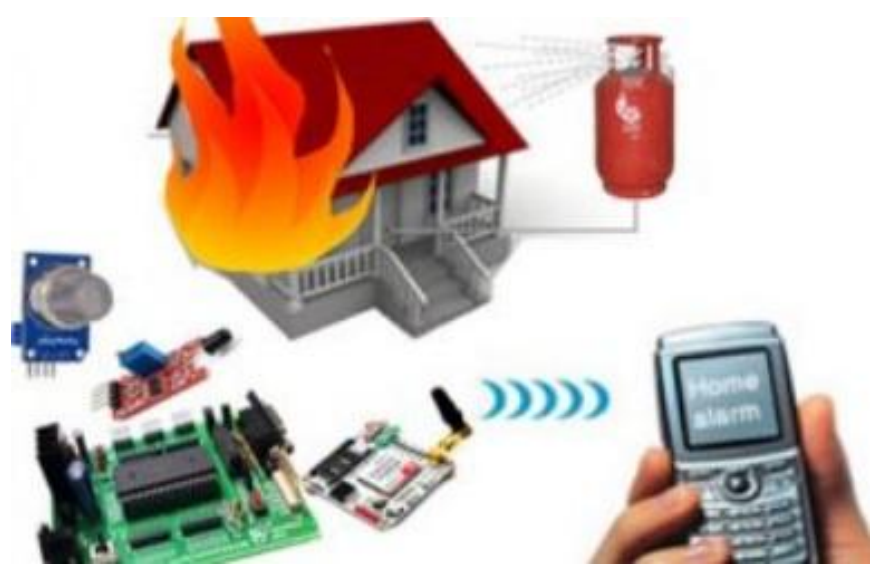

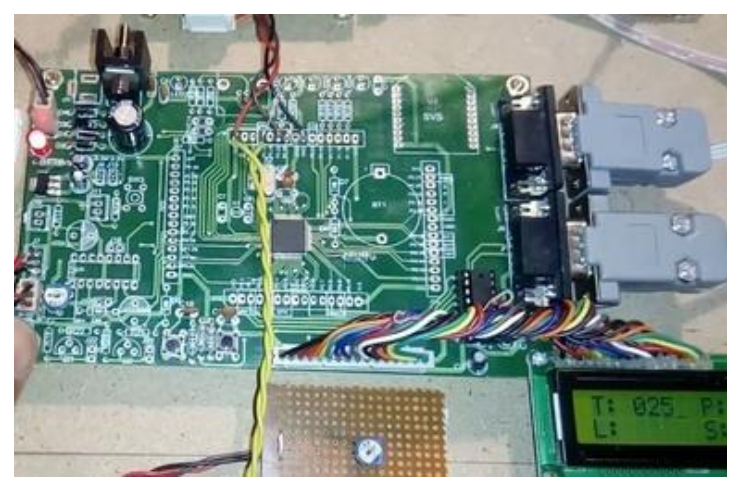

Figure.4: Sensor value detected

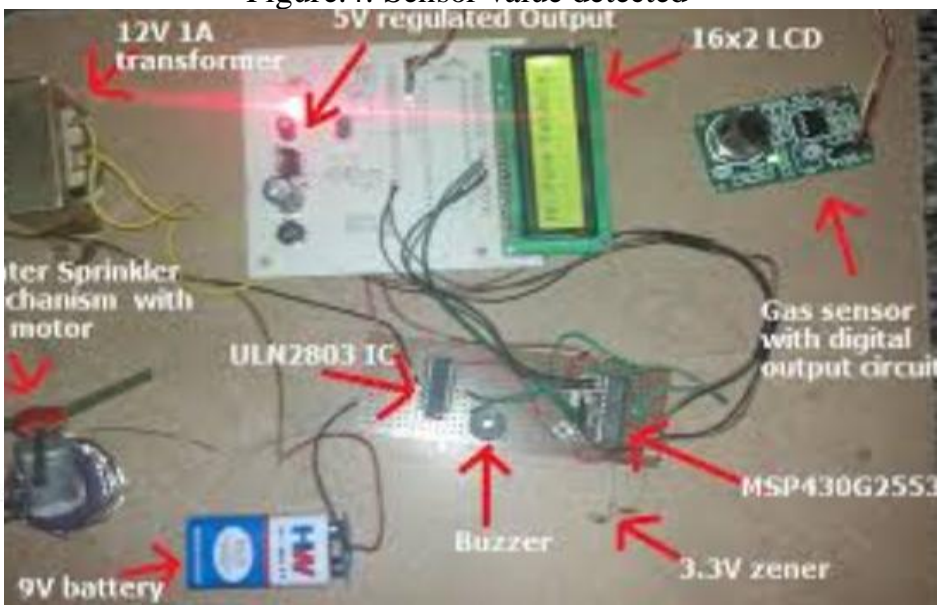

Figure.5. Several sensor values identified it will be presented

\section{CONCLUSION}

In this paper the recent innovation that helps previously, lessening the calamities created by chimney need been said. Those whole framework are planned and its adequacy and quantify capacity. Assuming that sensor engineering organization is enhanced after that the framework can ended up additional suitable Furthermore effective. Done each Assembling plant if this technique will a chance to be coordinated effectively chimney mishaps and more property will decrease lessen discernibly and the country's economy won't a chance to be sneak past such deplorable mishaps.

\section{REFERENCES}

[1] Sowah, Robert, et al. "Design and implementation of a fire detection and control system for automobiles using fuzzy logic." Industry Applications Society Annual Meeting, 2016 IEEE. IEEE, 2016.

[2] Nalajala, Paparao, et al. "Working Women Hand Held Safety Self Defense System Using IoT." (2017): 2051-2059.

[3] Chen, Thou-Ho, et al. "The smoke detection for early fire-alarming system base on video processing." Intelligent Information Hiding and Multimedia Signal Processing, 2006. IIH-MSP'06. International Conference on. IEEE, 2006.

[4] Fuzi, Mohd Faris Mohd, et al. "HOME FADS: A dedicated fire alert detection system using ZigBee wireless network." Control and System Graduate Research Colloquium (ICSGRC), 2014 IEEE 5th. IEEE, 2014.

[5] Kwon, Oh-Hyun, Sung-Min Cho, and Sun-Myung Hwang. "Design and implementation of fire detection system." Advanced Software Engineering and Its Applications, 2008. ASEA 2008. IEEE, 2008.

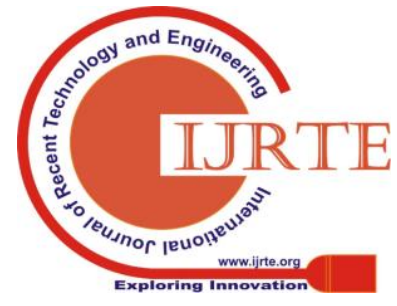




\section{Industry Fire Safety System using Embedded Technology with Internet of Things}

[6] Islam, Taoufikul, Hafiz Abdur Rahman, and Minhaz Ahmed Syrus. "Fire detection system with indoor localization using ZigBee based wireless sensor network." Informatics, Electronics \& Vision (ICIEV), 2015 International Conference on. IEEE, 2015.

[7] Paparao Nalajala, S Bhagya Lakshmi,"A Secured IoT Based Advanced Health Care System for Medical Field using Sensor Network", international journal of engineering \&Technlogoy, Vol. 7, Issue 2.20, (2018): 105-108.

[8] Dong, Wen-hui, et al. "Design of wireless automatic fire alarm system." Procedia Engineering 135 (2016): 413-417.

[9] Sun, Xiao-qian, and Ming-chun Luo. "Fire risk assessment for super high-rise buildings." Procedia engineering 71 (2014): 492-501.

[10] Godavarthi, Bhavana, Paparao Nalajala, and Vasavi Ganapuram. "Design and implementation of vehicle navigation system in urban environments using internet of things (IoT)." IOP Conference Series: Materials Science and Engineering. Vol. 225. No. 1. IOP Publishing, 2017.

[11] Yu, Liyang, Neng Wang, and Xiaoqiao Meng. "Real-time forest fire detection with wireless sensor networks." Wireless Communications, Networking and Mobile Computing, 2005. Proceedings. 2005 International Conference on. Vol. 2. IEEE, 2005. 